Canadian

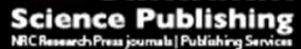

Canadian Journal of Forest Research Revue canadienne de recherche forestière

\title{
A multicentury dendrochronological reconstruction of western spruce budworm outbreaks in the Okanogan Highlands, northeastern Washington
}

\begin{tabular}{|r|l|}
\hline Journal: & Canadian Journal of Forest Research \\
\hline Manuscript ID & cjfr-2016-0399.R2 \\
\hline Manuscript Type: & Article \\
\hline Date Submitted by the Author: & 09-Jun-2017 \\
\hline Complete List of Authors: & $\begin{array}{l}\text { Ellis, Todd; Western Washington University, Environmental Studies } \\
\text { Flower, Aquila; Western Washington University, Department of } \\
\text { Environmental Studies }\end{array}$ \\
\hline Keyword: & $\begin{array}{l}\text { dendrochronology, dendroecology, drought, Pacific Northwest, western } \\
\text { spruce budworm }\end{array}$ \\
\hline $\begin{array}{r}\text { Is the invited manuscript for } \\
\text { consideration in a Special } \\
\text { Issue? : }\end{array}$ & N/A \\
\hline
\end{tabular}

SCHOLARONE

Manuscripts 
1 A multicentury dendrochronological reconstruction of western spruce budworm outbreaks

2 in the Okanogan Highlands, northeastern Washington

4 Todd M. Ellis and Aquila Flower

6 T.M. Ellis ${ }^{1}$ (ellist@students.wwu.edu) and A. Flower (Aquila.Flower@wwu.edu). Western

7 Washington University, Department of Environmental Studies, 516 High Street, MS 9085,

8 Bellingham, WA 98225, United States. Tel.: +1 3606503284.

9

$10{ }^{1}$ Corresponding author: Todd Ellis, 5609 Finch Dr., APT 320, Longview, WA 98632, United

11 States. E-mail: toddellis.wa@gmail.com. Tel.: +1 8308379684. 


\section{ABSTRACT}

14 The western spruce budworm (Choristoneura occidentalis Freeman) is recognized as the most

15 ecologically- and economically-damaging defoliator in western North America. Synchronous

16 western spruce budworm outbreaks can occur over much of a host species' range, causing

17 widespread limb and tree mortality, regeneration delays, and reduction in tree growth rates.

18 Observational outbreak records in northern Washington State extend back only to the mid-

19 twentieth century, limiting our understanding of this species' long-term population dynamics. In

20 this study, we used dendrochronological methods to reconstruct multi-century outbreak records

21 at four sites in the Okanogan Highlands of northeastern Washington State. We assessed long-

22 term changes in outbreak patterns and tested moisture availability as a potential driving factor of

23 western spruce budworm population dynamics. Outbreak synchrony was found to increase after

24 the late $19^{\text {th }}$ century, especially for high-intensity outbreaks, possibly due to anthropogenic

25 factors. Moisture availability records show that outbreaks tend to occur at the end of droughts.

26 As the variability of climate conditions is projected to increase, trending towards warm and dry

27 summer conditions, the intensity and frequency of high-intensity western spruce budworm

28 outbreaks may increase as well.

29 Key words: dendrochronology, dendroecology, drought, Pacific Northwest, western spruce

30 budworm 


\section{INTRODUCTION}

Western spruce budworm (Choristoneura occidentalis occidentalis Freeman) is

33 recognized as an ecologically- and economically-significant defoliating insect in western North

34 America (Fellin and Dewey 1982; Jenkins 2015). Regionally synchronous, decade-long

35 outbreaks over large areas lead to widespread ecological resource impacts. However, the causal

36 mechanisms driving this species' outbreak patterns and population dynamics remain under-

37 explored, with results often pointing to contradictory mechanisms. An understanding of the

38 western spruce budworm's (WSB) population dynamics is necessary to understand ecosystem

39 dynamics, predict climate change effects, and mitigate ecological and resource management

40 impacts. Multi-century records are needed to establish accurate outbreak histories and shed light

41 on climatic drivers of WSB's outbreak dynamics. While observational records of WSB activity

42 are only available back to the mid-20th century, variations in the width of annual tree rings can

43 serve as a proxy record of WSB defoliation. Dendrochronological records have been used to

44 reconstruct multi-century histories of WSB outbreak dynamics in the American Southwest

45 (Swetnam and Lynch 1993), central Rocky Mountains (Ryerson et al. 2003), and the Pacific

46 Northwest, including British Columbia (BC), Montana, Idaho, and Oregon (Swetnam et al. 1995;

47 Flower et al. 2014a; Axelson et al. 2015). A prominent gap in the spatial coverage of these

48 outbreak records exists in northern Washington State. In this paper, we present a

49 dendrochronological reconstruction of WSB outbreaks in Washington State's Okanogan

50 Highlands region.

51 The WSB consumes host foliage with a preference for current-year buds, staminate

52 flowers, and developing cones, causing reduction in growth rates, regeneration delays, and limb

53 and tree mortality after several years of repeated defoliation (Alfaro et al. 1982; Fellin and 
54 Dewey 1982). Douglas-fir (Pseudotsuga menziesii (Mirb.) Franco) and true firs (Abies spp.) are

55 the WSB's principal host species (Fellin and Dewey 1982). Host stands undergoing an outbreak

56 suffer a loss of biomass, increased rates of topkill, stem deformities, and tree mortality,

57 especially of saplings and seedlings (Fellin and Dewey 1982; Maclauchlan et al. 2006), and may

58 have increased susceptibility to subsequent insect outbreaks and pathogens (Alfaro et al. 1982).

59 Repeated outbreaks ultimately modify the composition and structure of forests, redistributing the

60 biomass and resources of susceptible host stands by removing photosynthetic tissue and reducing

61 the local carbohydrate supplies necessary for continued growth (Alfaro et al. 1982). For example,

62 Alfaro et al. (1982)'s study found that four outbreaks over roughly 85 years reduced the stand's

63 potential radial growth by about $12 \%$, with mortality rates ranging from $4.5 \%$ among mature

64 trees with a dominant canopy position to $39 \%$ among suppressed understory trees.

In the Pacific Northwest, WSB infestations are frequent in many coniferous stands, with

66 insect populations often continuously present at low endemic levels (Fellin and Dewey 1982;

67 Wickman 1992). Radial growth impacts from WSB outbreak defoliation tend to last, on average,

68 between 11 and 15 years (Lynch 2007). Aerial survey records suggest even shorter intervals of

69 WSB outbreaks, lasting as few as one to two years in some regions (USDA Forest Service 2014).

70 Quiescent period durations also vary across impacted regions, with an average of 32 to 40 years

71 between outbreaks (Swetnam et al. 1995; Lynch 2007).

WSB outbreaks tend to occur synchronously over large areas of the primary host species'

73 range (Ryerson et al. 2003; Flower et al. 2014a; Flower 2016). Large regions of synchronous or

74 near-synchronous WSB outbreaks are usually attributed to one or more of the following factors:

75 adult moth dispersal, exogenous stochastic factors such as climate, or trophic interactions with

76 similarly-synchronous or mobile populations (Peltonen et al. 2002). Dispersal capabilities 
77 strongly influence synchrony of population fluctuations at finer spatial scales (i.e., under 200

$78 \mathrm{~km}$ ), whereas climatic controls may be more a more important driver of synchrony at coarse

79 spatial scales, though the mechanisms behind observed patterns of synchrony are still not well

80 understood (Peltonen et al. 2002).

81 Over the course of the $20^{\text {th }}$ century, some regions have shown increasing outbreak

82 synchrony, severity, and/or intensity, possibly as a result of human impact (Swetnam and Lynch

83 1993; Swetnam et al. 1995; Ryerson et al. 2003; Campbell et al. 2006; Flower et al. 2014a;

84 2014b). The expansion of the extent and predominance of WSB's host species (both Douglas-fir

85 and true firs) due to historical human impacts (Hessburg et al. 1994; Keane et al. 2002) may be

86 linked to these changing outbreak dynamics. Selective harvesting of competing species, fire

87 exclusion, and livestock grazing are thought to have favored the establishment of WSB's host

88 species (Wickman 1992).

89 Climatic changes may have also played a role in these changing WSB outbreak

90 dynamics, and climatic variables are thought to be a primary driving force of WSB population

91 dynamics (Campbell 1993; Swetnam and Lynch 1993; Flower et al. 2014a). Fluctuations in

92 moisture availability are seen as the most important variable in effecting changes to WSB

93 population dynamics, with reduced moisture availability, and thus reduced needle moisture

94 content, linked to enhanced larval survival, growth, and reproductive rates (Clancy 1991;

95 Campbell 1993). In particular, the combination of increased moisture availability following

96 drought conditions may improve both the quality and quantity of the WSB's preferred foliage

97 during spring emergence (Flower et al. 2014a; Flower 2016). Previous studies have reported

98 inconsistent relationships between WSB outbreaks and climatic conditions, suggesting that the

99 WSB's response to climate variables may be regionally variable. For instance, Swetnam and 
100 Lynch (1993) found that high spring precipitation was an influencing factor in outbreak timing in

101 Colorado, while Flower et al. (2014a) found an increase in moisture stress was necessary in

102 initiating outbreaks in Oregon, Idaho, and Montana. The potential range of the WSB includes a

103 variety of climatic zones, with controlling climatic variables likely differing based on local- and

104 regional-level climate. Local records are thus needed to assess climatic influences on WSB

105 population dynamics in understudied areas such as northern Washington State.

106 The development of multi-century reconstructions contributes to the development of

107 forest management strategies that can cope with the economic and ecological impacts of

108 defoliating insects (Shepherd 1994). The purpose of this study is to uncover the Okanogan

109 Highlands landscape's history of WSB outbreaks, connecting an important geographic gap to

110 surrounding reconstructed outbreak records (e.g., Flower et al. 2014a; Axelson et al. 2015). We

111 characterize the frequency, periodicity, levels of synchrony, and intensity of the landscape's

112 outbreak history. Using these data with historical and reconstructed climate records, we enhance

113 our understanding of how moisture availability influences the WSB's population dynamics and

114 how changing climatic conditions may alter future WSB outbreak patterns.

\section{2. MATERIALS AND METHODS}

$116 \quad 2.1$ Study Area

117 We collected samples at six sites in the Okanogan Highlands of Okanogan National

118 Forest in August and October 2014 (Fig. 1). The Okanogan Highlands are characterized by an

119 arid, shrub-steppe environment, with vegetation dominated by Douglas-fir, with lesser amounts

120 of ponderosa pine (Pinus ponderosa Douglas ex P. and C. Lawson), western larch (Larix

121 occidentalis Nutt.), and grand fir (Abies grandis (Dougl. ex D. Don) Lindl.; McNab and Avers

122 1994). Elevations at our sites ranged between 1000 and $1600 \mathrm{~m}$. The geological setting of most 
123 study sites was gneiss bedrock, with the easternmost host site identified as basalt (Lasmanis and

124 Cheney 1994). Using ClimateWNA's 30-year climate normals for 1981-2010, our site records

125 report average temperatures between from $-6.2^{\circ} \mathrm{C}$ to $15.8^{\circ} \mathrm{C}$ in the coldest and warmest months,

126 respectively; average annual precipitation was recorded as $451 \mathrm{~mm}( \pm 62 \mathrm{~mm})$, with $175 \mathrm{~mm}$

$127( \pm 5.2 \mathrm{~mm})$ occurring during summer months (Wang et al. 2012).

\subsection{Sampling Strategy}

We collected samples at paired host and non-host sites. Samples collected at non-host

130 sites were used to create a control chronology. This approach allowed us to isolate the defoliation

131 signal contained in host tree-ring chronologies. We chose Douglas-fir as a host species due to its

132 wide range in the Okanogan Highlands and its susceptibility to WSB outbreaks (Mason et al.

133 1997). We chose ponderosa pine as our non-host species. Douglas-fir and ponderosa pine have

134 overlapping geographic ranges and similar responses to climate (Watson \& Luckman 2002; Chen

135 et al. 2010), but ponderosa pine is rarely defoliated by the WSB (Fellin and Dewey 1982).

136 We selected potential study areas with a history of frequent WSB outbreaks based on

137 annual USFS Insect and Disease Survey data dating back to 1947 (Williams and Birdsey 2003;

138 USDA Forest Service 2014). Within those potential study areas, we selected specific study sites

139 using satellite imagery and in-situ evidence. We selectively targeted sites separated by

140 significant topographic features such as mountains or valleys to insure adequate spatial coverage.

141 We targeted stands with multi-century records, with the oldest trees ideally dating to at least 300

142 years (Table 1). We avoided host and non-host stands with extensive recent disturbances such as

143 logging or fire damage.

144 We extracted two increment cores per tree. We avoided reaction-wood by coring parallel

145 to the slope contour at 1.3 meters above ground, except where impossible due to difficult 
146 topography. We sampled 15-20 trees from each of our four host stands for a total of 69 trees

147 (Table 1). Within sites, we selectively-sampled based on visual assessment, using criteria that

148 included old-age cues such as flattened tops, spiral-grained bark, large lower limbs, and the

149 diameter at breast height being at least $40 \mathrm{~cm}$. We avoided samples that included any indication

150 of significant damage (e.g., fire scars) that could potentially distort the growth patterns.

151 For non-host stands, we sampled between six and 17 trees from three sites to maximize

152 the visible impacts of defoliation (Table 1). To produce the longest possible record, we collected

153 non-host samples with the intention of creating a single landscape-wide chronology for use with

154 each host site. Monospecific non-host stands were preferentially targeted to avoid any growth

155 release from species affected by defoliation or competition (Swetnam et al. 1995). Old-growth

156 ponderosa pine stands are, however, aggressively-maintained by the USFS, who selectively

157 harvests young growth around older pine trees (Nash, personal correspondence 2014). Because

158 of these issues, the age of non-host stands superseded the importance of monospecificity and we

159 include six trees from our Turner Lake site despite the presence of Douglas-fir.

2.3 Sample preparation and laboratory analysis

161 We prepared our samples using standard dendrochronological techniques (Speer 2010).

162 We dried and glued core samples to wooden core mounts before surfacing with 120-, 220-, 320-

163 ,400-, and 600-grit sandpaper. We first visually crossdated each sample from the bark inwards

164 using a microscope. We then scanned and measured to the nearest $0.001 \mathrm{~mm}$ using Cybis'

165 CooRecorder and CDendro software (Larsson and Larsson 2014). We used CDendro to visually

166 identify known outbreak periods (Swetnam et al. 1995), and create master chronologies for each

167 host and non-host site. CDendro allowed for the creation of a master chronology to be used with

168 any sample measurements, minimizing the errors caused by our visual interpretation (Larsson 
169 and Larsson 2014). We statistically crossdated our ring-width chronologies using the R package $170 \quad d p l R(B u n n$ 2008; R Core Team 2013).

171 We used the $d p l R$ package to detrend raw measurements for host and non-host sites using

172 a 100-year cubic smoothing spline (Bunn 2008). Since WSB growth impacts are inherently

173 autocorrelative due to the decadal-plus temporal fingerprint of WSB outbreaks, we chose not to

174 remove autocorrelation from our host site chronologies. This method of standardization ensures

175 decadal impacts like WSB outbreaks will be maintained, while correcting for year-to-year age-

176 related growth trends (Cook 1985). Resultant ring-width indices were averaged together by tree,

177 and used to create mean site chronologies for host and non-host sites. A principal components

178 analysis was run on the standard and residual (i.e., prewhitened using autoregressive modeling)

179 non-host chronologies to extract the common signal shared by the non-host trees. We chose the

180 first principal component of our three standard non-host master chronologies for our outbreak

181 reconstructions because it explained the highest shared variance (81\%) and correlated most

182 strongly with our host chronologies.

$183 \quad 2.4$ Outbreak Reconstructions

184 We visually compared ring-width measurements with historical USFS records of known

185 outbreak periods within the Okanogan Highlands (USDA Forest Service 2014), as well as nearby

186 dendrochronological reconstructed outbreak dates (e.g., Campbell et al. 2006). Like crossdating,

187 this visual comparison provided us with a first step to identifying periods of growth suppression

188 at tree-level. Outbreaks are often visible as long-term growth suppression periods in the host tree

189 chronologies that are not apparent in the landscape's non-host chronology. To statistically-

190 reconstruct outbreak records, we first subtracted climatic noise from each host tree using the

191 equation: 
Corrected Index $=I_{h t}-\frac{\sigma_{h}}{\sigma_{n}}\left(I_{n t}-\bar{I}_{n}\right)$

193 where $I_{\mathrm{h}}$ is the host trees' ring-width index for each individual year $(t), \sigma_{\mathrm{h}}$ and $\sigma_{\mathrm{n}}$ are the standard

194 deviations of the individual host tree series and the landscape-wide non-host series' common

195 period, $I_{\mathrm{n}}$ is the non-host control index for each year $(t)$, and $\bar{I}_{\mathrm{n}}$ is the mean for the non-host index

196 for the common period. The output of this equation created a new value for each year of growth

197 across host trees, where positive or negative values represent growth above or below the

198 expected growth from climatic factors alone (Nash et al. 1975; Swetnam et al. 1985). Similarities

199 between the corrected site indices during their shared common periods (1719-2014 for three

200 sites, 1796-2014 for all four) were checked using Pearson's correlation coefficients.

201 To develop an appropriate set of criteria for identifying WSB outbreaks, we normalized

202 the corrected tree series and identified outbreak-length periods of low growth. We did not record

203 non-consecutive years of positive growth as outbreak interruptions, as non-consecutive positive

204 growth years are common within outbreak periods (Swetnam et al. 1995). Minimum thresholds

205 for WSB outbreak length vary by region, typically ranging between four to eight years of

206 sustained below-average growth, with at least one year of growth at least 1.28 standard

207 deviations below the long-term mean ring width (Swetnam et al. 1995). Another defoliating

208 insect, the Douglas-fir tussock moth (Orgyia pseudotsugata McDunnough), can create similar

209 outbreak patterns in Douglas-fir ring width records, but their outbreaks only last up to three years

210 (Brubaker 1978), which makes four-year outbreak durations the shortest desirable outbreak

211 length for separating the WSB signal from similar defoliating insects (Swetnam et al. 1995;

212 Mason et al. 1997). We tested a minimum outbreak duration criterion of between four and eight

213 years against observational outbreak records and chose four years as the most reflective of 
214 historical outbreaks. A minimum growth reduction severity criterion of 1.28 standard deviations

215 below the long-term mean was used for all reconstructions. Outbreak periods were identified

216 based on these criteria for each individual tree, resulting in an annually resolved binary record of

217 outbreak or non-outbreak conditions.

218 We standardized the binary, tree-level outbreak data into the percentage of a site's sample

219 population reporting infestation year-to-year. Since outbreak reconstructions tend to regularly

220 report some level of tree infestation reflecting endemic WSB populations, small-scale population

221 changes, or background noise, we explored multiple outbreak intensity thresholds for each site

222 between $30-80 \%$ of sampled trees reporting infestation. We compared the resultant outbreak

223 time series with historical air and ground survey records (McComb 1979; Westfall and Ebata

224 2014; Jenkins 2015; Mehmel, personal correspondence 2015), with which a 40\% threshold best

225 identified the start of moderate outbreak conditions. Additionally, we used thresholds of $60 \%$

226 and $80 \%$ to identify high and very high outbreak intensities, respectively, which could gauge

227 how intensity patterns have changed over the entire time series for each host site. The resultant

228 corrected chronology provides measures of intensity, synchrony (the co-occurrence of outbreaks

229 across our sites), and duration (the length of time when growth was below the corrected indices'

230 potential growth) of outbreak disturbances within and between stands. We defined landscape-

231 wide outbreaks as periods in which at least two of our four sites recorded coincident outbreaks

232 for a minimum of two consecutive years.

$233 \quad 2.5$ Statistical Analysis

$234 \quad$ 2.5.1 Outbreak Characteristics

235 We averaged outbreak duration and intensity for site and landscape-wide outbreak

236 records, and checked for temporal changes by dividing both duration and intensity data into two 
237 similar-sized groups: Before 1870 and after 1869. This separation would also roughly coincide

238 with the introduction of forestry practices like harvesting in the Washington Territory (Chiang

239 and Reese 2002). As historical records prior to 1970 either aren't reliable or don't exist for our

240 study area, this breakpoint provides a loose representation for when Euro-American settlers'

241 influences may have begun affecting regional outbreak patterns (Johnson and Ross 2008). We

242 conducted ANOVA on stand-level normalized corrected indices to test for differences between

243 Douglas-fir's growth response during and outside of outbreak conditions. Based on the results of

244 the Shapiro-Wilk normality test, which indicated a non-normal distribution, we chose to use a

245 Kruskal-Wallis nonparametric ANOVA.

\subsubsection{Outbreak Synchrony Among Sites}

We assessed the level of synchrony between stand-level outbreak histories (i.e., the

248 percent of each site's trees recording an outbreak) using Pearson's correlation coefficients.

249 Despite the high autocorrelation inherent in synchrony records, which makes estimation of

250 statistical significance unreliable, the correlation coefficients can be used as an approximate

251 index of sites' outbreak synchrony over time (Buonaccorsi et al. 2001). This simple analysis was

252 conducted on the percent of each site's sampled trees recording outbreaks over both of our

253 common periods (i.e., 1719-2014 and 1796-2014).

254 We used a modified one-dimensional Ripley's K-function (Gavin et al. 2006) to test

255 whether discrete outbreak events were independent of one another over increasing bidirectional

256 temporal lags. Years of outbreak occurrences, initiations, and cessations for our three oldest sites'

257 common period were input into K1D v1.2 software (Gavin 2010). The youngest site, SMD, was

258 removed from this method to retain as much of our landscape's record as possible without

259 sacrificing too much of our sample size (Table 1). This method checks for co-occurrence of 
260 outbreak events between any of the sites over increasingly long temporal windows until the

261 bidirectional window is half the length of the total record length, with the resultant $\mathrm{K}$ and $\mathrm{L}$

262 functions providing a measure of outbreak synchrony or asynchrony over increasing temporal

263 scales. To test for statistical significance, we ran 1000 simulations with a .95 confidence

264 envelope using a circular randomization, with random year data added to all site records. We

265 also separated the 1719 common period around the 1870 breakpoint for all three of our intensity

266 thresholds - i.e., moderate (40\%), high (60\%), and very high (80\%). This gives us a rough

267 estimation of how site interactions may have changed before and after major human impacts

268 began affecting the region.

\subsubsection{Climate-Outbreak Associations}

270 We conducted a Pearson's cross-correlation analysis on both standard and residual host

271 and non-host chronologies against landscape-wide instrumental and reconstructed climate

272 records to determine if the chronologies expressed the similar climate responses necessary for

273 outbreak reconstructions (Speer 2010). Our climate records included both historical (1895-2014;

274 NOAA 2015) and reconstructed (1685-2003; Cook et al. 2004) Palmer Drought Severity Indices

275 (PDSI; Palmer 1965). PDSI records provide a measure of summer (i.e., between June and

276 August) moisture stress based on soil type, precipitation, and temperature (Palmer 1965). Cook

277 et al.'s (2004) multi-century, gridded PDSI reconstruction network is available for $2.5^{\circ}$ by $2.5^{\circ}$

278 gridcells, with our landscape's data drawn from grid 43 (Cook et al. 2004). In addition to PDSI

279 data, we used historical precipitation data for water years (i.e., previous October to current

280 September) and growing years (April to September of the current year) for the Okanogan Big

281 Bend (Climate Division 7) area (NOAA 2015).

282 To identify climatic conditions associated with WSB outbreak initiations and cessations, 
283 we used superposed epoch analysis to identify patterns of climatic conditions associated with

284 outbreak initiation and cessation dates. Superposed epoch analysis uses event years (i.e.,

285 outbreak initiation and cessation dates) with time series data and designated temporal lags to test

286 for significant departures from the mean (Grissino-Mayer 2001). We defined initiation dates as

287 the first of two or more consecutive outbreak years following a gap of at least two years without

288 recorded outbreaks, and cessation dates as the first of at least three years of non-outbreak

289 conditions following an outbreak. However, we acknowledge that these dates are approximate,

290 as there may be a lag of up to three years between the actual date of outbreak initiations or

291 cessations and the onset of resulting radial growth impacts (Alfaro et al. 1982). We quantified

292 climate anomalies using both historical and reconstructed climate records for an eleven-year

293 window centered on outbreak events. Statistical significance was assessed with 1000 Monte

294 Carlo simulations using $d p l R$ (Bunn 2008). To assess longer-term patterns of climate associated

295 with outbreaks, we conducted paired, two-sample t-tests to test for differences between PDSI

296 data associated with outbreak conditions against non-outbreak conditions.

\section{RESULTS}

\subsection{Dendrochronological characteristics and Outbreak histories}

A total of 69 host trees and 32 non-host trees were sampled over our six sites. Our

300 landscape-wide non-host chronology dated to 1685 . Host site records with at least two trees

301 started between 1685 and 1796 (Table 1). Interseries correlation (Pearson's $r ; p<0.01$ for all

302 pairs) for our host sites ranged between 0.650 and 0.780 , while non-host sites ranged between

3030.627 and 0.760 . Correlation coefficients (Pearson's $r$ ) between both our host and non-host

304 chronologies and climate data supported the use of our sites for outbreak reconstructions (Table

305 2). All of our host site residual chronologies, as well as our landscape-wide residual non-host 
306 chronology, reported significant $(p<0.05)$, positive relationships with reconstructed and

307 historical PDSI, as well as water-year precipitation for the current and preceding year. The

308 relationship with temperature returned less significance, although the average July temperature

309 had a significant, negative relationship with all but our non-host chronology (Table 2).

310 Outbreak durations, based on sites with at least $40 \%$ of their sampled trees reporting

311 outbreak conditions, ranged from two to 19 years across sites, with mean site-level outbreak

312 durations ranging between $8.6( \pm 3.9)$ and $10.7( \pm 5.8)$ years by site (Table 3$)$. Quiescent periods

313 lasted between four and 52 years, with site means ranging between $11.4( \pm 7.5)$ and $20.0( \pm 10.1)$

314 years. The average for the landscape-wide outbreak duration and quiescent period length was 8.3

$315( \pm 4.3)$ and $13.3( \pm 11.0)$ years, respectively. The Kruskal-Wallis ANOVA analysis suggested

316 stand-level corrected indices during and between outbreaks are significantly different (Table 3).

317 All four of our sites showed changes between the early (1685-1869) and modern (1870-2014)

318 periods, with more years reporting outbreaks in the modern period.

$319 \quad 3.2$ Inter-site outbreak synchrony

320 During the 330 years covered by our landscape-wide reconstruction (1685-2014), all

321 reporting sites experienced identical outbreak conditions (either outbreak or non-outbreak)

322 during 184 individual years (55.8\% of years in the common period). There were a total of 16

323 landscape-wide outbreaks (i.e., periods in which at least two sites shared concurrent outbreak

324 conditions) covering 130 years (39.4\%) of the total 330 years. Outbreak and non-outbreak

325 conditions tended to occur synchronously or near-synchronously (Fig. 2), with synchrony

326 increasing after 1869 . Using our moderate intensity threshold, the early period included $43.8 \%$ of

327 landscape-wide outbreak years (i.e., years with outbreaks at two or more sites), and the modern

328 period $56.2 \%$. Based on the moderate outbreak threshold, there has been little to no change in 
329 outbreak synchrony since the start of the reconstruction. However, analysis using higher intensity

330 thresholds revealed an increase in high-intensity, synchronous outbreaks in the modern period

331 (Table 4). Using our very high intensity threshold, all landscape-wide synchronous outbreaks

332 occurred after 1869 (1938, 1992, and 2010). For our three oldest sites, very high intensity

333 outbreaks occurred in $0 \%$ to $5.9 \%$ of the total early period years, and between $6.9 \%$ and $14.5 \%$

334 of the modern period years.

335 Pearson's correlation of outbreak histories also revealed a pattern of synchrony. The

336 average inter-site correlation for the three oldest sites' outbreak histories (i.e., MPD, TMD and

337 VLD) was 0.60 , while all four sites yielded a correlation of 0.71 . The Tunk Mountain Douglas-

338 fir (TMD) reduces both periods' correlations likely due to a unique period of asynchronous,

339 stand-specific outbreaks during the mid- $19^{\text {th }}$ century also recorded in nearby outbreak

340 reconstructions (Fig. 2; Campbell et al. 2006; Axelson et al. 2015).

341 The modified one-dimensional K-statistic for all outbreak years was statistically

342 significant $(p<0.05)$ for up to 11 years for our three sites dating to 1719 (Fig. 3). Initiation and

343 cessation dates for the 1719 common period showed significant temporal synchrony over

344 windows up to six and nine years, respectively, with a higher degree of synchrony for initiation

345 events than cessation dates or all outbreak years (Fig. 4). In the early period (1719-1869), no

346 significant synchrony was found for outbreaks using our high and very high outbreak intensities

347 (Fig. 3). All outbreak intensities reported between up to nine to 24 years of synchrony for the late

348 period records (1870-2014).

\subsection{Climatic influences on outbreaks}

350 Outbreak initiation dates were preceded by between two and five warm-dry years at all

351 sites, with initiation dates tending to occur in cooler, wetter years (Fig. 5). While no site reported 
352 statistically-significant cool-wet years in the five years following an initiation event, all sites still

353 showed a shift towards cool-wet conditions. Our landscape-scale outbreak record (1685-2014)

354 shows a statistically-significant warm-dry anomaly in the second year preceding initiation events

355 (Fig. 6). Paired, two-sample t-tests revealed significantly $(t=2.83, p=0.01)$ cooler/wetter

356 conditions during outbreak years (mean PDSI $=0.51)$ than during non-outbreak years (mean

357 PDSI $=-0.26)$.

358 We identified a tendency for shifts from cool-wet to warm-dry conditions during

359 outbreak cessation years (Fig. 5). Between three and four sites reported cool-wet conditions in

360 each of the five years preceding outbreak cessation dates, with two sites reporting at least one

361 significant year of cool-wet conditions. The landscape-wide outbreak record shows the same

362 pattern, with cool-wet conditions shifting to warm-dry conditions one year prior to cessation

363 dates.

364 We saw the same patterns for historical PDSI data (1895-2014) from climate station

365 records (Fig. 5). All sites reported warm-dry conditions for at least three years preceding

366 outbreak initiations, with one site reporting significance for three years. Following outbreak

367 initiations, all sites reported cool-wet periods for at least two years, with three sites reporting

368 significant cool-wet conditions. Three sites reported warm-dry conditions during outbreak

369 initiation events. All sites reported warm-dry conditions at least once in the two years following

370 outbreak initiations, with one instance of significance. The landscape-wide outbreak record

371 exhibits a statistically significant pattern of warm-dry conditions two years prior to initiation

372 events, with significant cool-wet periods between three and five years after initiation dates (Fig.

373 6). All four of our sites and the landscape-wide outbreak record showed between one and four

374 significant years of cool-wet conditions prior to cessation dates using the historical PDSI data, 
375 with no sites returning significant conditions following cessation dates (Fig. 6).

\section{Discussion}

\subsection{Outbreak histories}

We were able to successfully reconstruct 330 years of WSB outbreak history for the

379 Okanogan Highlands. Our reconstructed outbreak dates closely match those recorded in

380 historical documents and aerial survey reports. Since accurate historical records for our study

381 area are only available after the 1970s, nearby historical records for southern BC were used

382 alongside our landscape's records to check against our outbreak reconstructions. Harris et al.

383 (1985) used historical records to identify WSB outbreaks either as hectares affected, percent of

384 trees infested, or severity of impact (e.g., existence of topkill) in the Canadian Cascade Range for

385 the 1923-1930, 1943-1958, and 1977-1983 periods, with all but the earliest outbreak period not

386 reflected in our data. WSB defoliation and population data were not recorded for the region

387 between 1931 and 1942, possibly explaining the discrepancy between our reconstructions and

388 historical records. The three most recent outbreaks (1975-1983, 1990-2001, 2009-present)

389 concur with the USFS insect survey data and other WSB outbreak studies from the Pacific

390 Northwest (USDA Forest Service 1977; McComb 1979; Alfaro et al. 2014; USDA Forest

391 Service 2014; Axelson et al. 2015). Some inconsistencies between aerial survey records and our

392 reconstructed outbreak dates may be due in part to inconsistent quality control and accuracy in

393 identifying insect outbreaks via aerial survey (Johnson and Ross 2008).

394 Climate-growth analysis showed that the annual radial growth rates of both host and non-

395 host trees were significantly limited by moisture stress (Table 2). Similar to Chen et al. (2010),

396 we found positive correlation between our trees' radial growth and precipitation values, as well

397 as negative correlation with temperature values. This suggests that warm, dry conditions inhibit 
398 radial growth rates similarly in both ponderosa pine and Douglas-fir, while cool, wet conditions 399 promote radial growth rates. The similarity in the climate-growth responses of the two species 400 supports our use of ponderosa pine as a proxy for climatic variability in the construction of our 401 corrected indices.

402 Douglas-fir dwarf mistletoe (Arceuthobium douglasii Engelm.) was prevalent in 11 of our 403 sampled trees from MPD and VLD, but no associated radial growth anomaly could be identified 404 (Hadfield et al. 2000). External signs of severe Douglas-fir dwarf mistletoe infection are known 405 to overlap with signs of long-term WSB infestation, but radial growth impacts are unrelated 406 (Hadfield et al. 2000). The 1975-1983 landscape-wide outbreak shows no lag between our 407 reconstruction and historical records for the initiation year, which may be the result of signal 408 contamination by Douglas-fir tussock moth's landscape-wide 1970-1974 outbreak (Mehmel, 409 personal correspondence 2014). The Douglas-fir tussock moth impacts trees' growth response 410 similarly to the WSB, which could replace the lag between outbreak initiation and trees' growth 411 response we expect to see with WSB outbreaks (Brubaker 1978). Such overlaps are rare but 412 always a potential issue with WSB studies, and this is the only known case in our study site of 413 overlapping Douglas-fir tussock moth and WSB outbreak records overlapping. Since the 414 relationship between our reconstructed outbreak history and moisture availability follows other 415 studies (e.g., Swetnam and Lynch 1993; Flower et al. 2014a), we can safely assume the Douglas416 fir tussock moth's influence on our reconstructions is minimal, but we acknowledge that a more 417 conservative interpretation of our record would be that this is a history of defoliation events in 418 general.

Our outbreak reconstructions resulted in outbreak patterns similar to those seen in nearby 420 regions. The landscape's average outbreak duration of 8.3 years roughly matches nearby studies 
421 in the Pacific Northwest (Campbell et al. 2006: 12 years; Flower et al. 2014a: 12 years; Alfaro et

422 al. 2014: 7 years; Axelson et al. 2015: 11.2 years), while the landscape's quiescent period of 13.3

423 years was the lowest among nearby studies, which ranged between 15 to 64.2 years.

424

425

426

427

428

429

430

431

432

433

434

435

436 437 Maclauchlan and Brooks 2009).

438

439

440

441

442

443

\subsection{Inter-site outbreak synchrony and driving factors}

Our reconstructions show that WSB outbreaks have been occurring synchronously in the region back to at least 1685 . The landscape-wide outbreak records showed 16 instances of synchronous outbreaks occurring between 1685 and 2014. Similar to other studies, our region

has seen an increase in outbreak synchrony, but not duration or frequency after the $19^{\text {th }}$ century (Ryerson et al. 2003; Alfaro et al. 2014). The increase in outbreak synchrony is likely related to anthropogenic climate change and changing land-use regimes. Climate change over the $20^{\text {th }}$ century has promoted climatic variability and aridity (Cook et al. 2004), with warming

temperatures, regardless of changes to moisture availability, effecting an increase in the moisture stress response of trees during summer months (Coops and Waring 2011). Changing land-use regimes have increased forest homogenization by favoring expansion and increased density of the WSB's host tree species through practices such as fire exclusion and logging (Swetnam and Lynch 1993; Wickman 1992; Swetnam et al. 1995; Hessburg et al. 1994; Keane et al. 2002;

At our sites, a highly asynchronous period of site-specific outbreaks occurred between 1820-1870, during which only one site (TMD) was impacted by outbreaks. This asynchronous period is also reported by nearby records (Harris et al. 1985; Campbell et al. 2006; Axelson et al. 2015), and may be at least partially attributable to alternating regimes of warm and cool sea surface temperatures driven by the Pacific Decadal Oscillation teleconnections between 18401923 affecting local climate variables like PDSI (Gedalof and Smith 2001; Campbell et al. 
444 2006).

445 Higher-intensity outbreaks at both site- and landscape-levels were more frequent in the

446 last century than in previous centuries. The degree of synchrony tended to increase with the

447 intensity threshold used, particularly when looking at outbreaks that occurred during the late

448 period (1870-2014). This clustering of synchronous events towards the $20^{\text {th }}$ century suggests the

449 patterns of synchrony we see in the full records (i.e., 1719-2014) for high and very high

450 intensities may not accurately reflect the clustered pattern, due to the method of randomization

451 built into the K1D software being less effective at finding patterns with increasingly-clustered

452 temporal events (Gavin, personal communication 2016). The highest-tested intensity threshold

453 had no landscape-wide outbreak events prior to the $20^{\text {th }}$ century, making the degree of frequency

454 and synchrony in the late period unprecedented. Three landscape-wide outbreaks of very high

455 intensity occurred among our sites, and all of them in the last century (during the 1940s, 1990s,

456 and 2010s), strongly suggesting anthropogenic impacts such as climate change or land-use

457 practices play a primary role.

458 The drivers of synchronous insect outbreaks are not fully understood, but there is support

459 for the role of both fine-scale (i.e., up to $200 \mathrm{~km}$, but strongest up to $100 \mathrm{~km}$ ) dispersal abilities

460 and exogenous, abiotic stochastic factors in driving WSB and similar insect outbreak synchrony

461 (Peltonen et al. 2002; Liebhold et al. 2004). WSB and similar moths have been found capable of

462 flying hundreds of km in above-canopy winds (Greenbank et al. 1980; Campbell 1993), and

463 synchrony of outbreak records is highest among sites less than 100-200 km apart (Peltonen et al.

464 2002), suggesting a moderate dispersal ability constrained by geography such as mountainous

465 terrain. Since our sites were all within $50 \mathrm{~km}$ of one another, it could be assumed that dispersal

466 plays a role in our outbreak synchrony. Dispersal abilities are likely influenced by local land-use 
467 histories, as well, which have promoted the expansion and growth of Douglas-fir over non-host 468 species like ponderosa pine since the late $19^{\text {th }}$ century. Coupled with fire exclusion, this has led 469 to an increase in host range and canopy density (Swetnam and Lynch 1993; Maclauchlan and 470 Brooks 2009). This homogenization of host forests could also increase dispersal abilities over 471 smaller areas with limited topographic barriers like the Okanogan Highlands, potentially leading

472 to higher population densities during outbreak conditions (Willhite and Stock 1983). Another

473 potential factor, the influence of trophic interactions on WSB populations, has been

474 underexplored in research, but is assumed as similarly limited to local area due to the mobility of 475 insectivores nearly mirroring prey dispersal abilities (Peltonen et al. 2002).

476 The Moran theorem proposes that the spatial and temporal autocorrelation of abiotic, 477 exogenous factors help to synchronize biotic populations over a landscape (Moran 1953).

478 Regional climatic stochasticity has been found to be the dominant influence synchronizing many 479 insect species’ population dynamics, particularly over larger spatial scales (Peltonen et al. 2002;

480 Swetnam and Lynch 1993; Flower et al. 2014a). Flower (2016) linked widespread synchrony of 481 WSB outbreaks with fluctuations in moisture availability. Synchrony across the scale of the 482 landscape we analyzed could be due to either dispersal or climatic controls, or, most likely, a 483 combination of the two. However, our outbreak history is strikingly similar to outbreak records 484 at other sites across much of western North America. We found that all of our outbreak records 485 between 1700 and 1990 coincide with synchronous outbreaks recorded in three to six other 486 regions (central British Columbia, southern Colorado, northern New Mexico, Idaho, Oregon, 487 and/or Montana). Specifically the landscape-wide outbreaks that occurred during 1715-1717, 488 1742-1752, 1760-1768, 1775-1777, 1785-1797, 1809-1814, 1819-1829, 1871-1883, 1892-1898, 489 1901-1910, 1938-1956, 1960-1963, and 1975-1983 all fall within time periods of widespread, 
490 synchronous outbreaks (Flower 2016). This scale of synchrony suggests that climate, which

491 varies over a similarly large geographic scale, plays a role in the synchronization of WSB

492 outbreaks.

\subsection{Outbreaks and climatic variability}

WSB outbreak initiation dates show a distinct trend of transitioning climate from warm-

495 dry conditions to cool-wet conditions: All four of our sites showed strong warm-dry conditions

496 in two or more years immediately prior to initiation events (Fig. 5). During and after initiation

497 dates, climate tended towards cool-wet conditions. This pattern of cool-wet climate conditions

498 during outbreak conditions has been identified by other dendrochronological studies (Swetnam

499 and Lynch 1993; Swetnam et al. 1995; Ryerson et al. 2003; Flower et al. 2014a). Since a variable

500 lag of one to three years for both initiation and cessation dates usually exists between the actual

501 time of an infestation's initiation / cessation and a tree's radial growth impacts (Alfaro et al.

502 1982; Swetnam et al. 1995; Mason et al. 1997), this suggests that the warm-dry years prior to an

503 outbreak initiation represent the climatic conditions driving WSB outbreak initiations, and the

504 subsequent transition to cool-wet conditions are necessary to sustain outbreak-level populations.

505 This is consistent with previous studies that linked warm-dry conditions to outbreak initiation

506 timing (Hard et al. 1980; Thomson et al. 1984; Campbell 1993; Flower et al. 2014a).

507 The transitional climate conditions we found associated with outbreak initiations supports

508 the nonlinear pulsed plant stress hypothesis (Huberty and Denno 2004; Mody et al. 2009), in

509 which temporal variability in moisture stress was proposed as crucial for initiating and

510 subsequently sustaining insect outbreaks. Moderate drought stress has been found to favor WSB

511 and similar herbivorous insects' growth and reproductive rates, as well as larval survival, by

512 increasing foliar concentrations of nitrogen, sugars, and other favorable compounds (Mattson 
513 and Haack 1987; Campbell 1993). These changes to foliage composition prior to transitioning

514 climate conditions would benefit the growth and survival of WSB during larval stages by

515 favoring the species' diet during moderate drought stress, and subsequently allowing for

516 increased needle production and decreased needle toughness during sustained cool-wet

517 conditions (Gower et al. 1992). This relationship can, however, reverse with prolonged outbreak

518 conditions or increasing outbreak severity (Mattson and Haack 1987; Campbell 1993; Hubert

519 and Denno 2004). Our results indicate the non-linear relationships described by the pulsed plant

520 hypothesis as the strongest explanation for WSB outbreak dynamics over multi-century records.

521 Cessation dates, like initiation dates, are expected to show a one- to three-year lag

522 between years of outbreak conditions and a tree's return to normal growth conditions during the

523 recorded cessation date (Swetnam et al. 1995; Mason et al. 1997). This suggests that the five

524 years of sustained cool-wet conditions recorded at our sites should represent the conditions in

525 which outbreak-level WSB populations crashed (Fig. 5). Cessation dates with defoliating species

526 like WSB are typically attributed to a loss of food from sustained overpopulation and trophic

527 interactions with natural predators, parasites, or pathogens (Nealis 2015). As available needles

528 become more sparse or difficult to mine, the WSB population density inevitably dips, while

529 predators, parasitoids, and pathogens that prey on WSB are able to maintain population densities

530 and increasingly contribute to WSB population losses (Nealis 2015). Despite also showing a

531 transitioning climate around cessation dates, the transition to warm-dry conditions after cessation

532 would not have a causal relationship with the WSB's population crashes. However, since our

533 superposed epoch analysis consistently reported cool-wet conditions at three to four of our sites

534 over five years prior to cessation dates, it's likely that long-term maintenance of cool-wet

535 conditions plays a role in WSB population crashes via climatic effects on trophic interactions, 
536 food loss, emergence- and budburst-timing, and physically damaging local weather conditions

537 (Fellin and Dewey 1982; Campbell 1993).

\section{5. CONCLUSION}

WSB outbreaks have been occurring synchronously in the Okanogan Highlands since at least 1685 . Outbreak synchrony across the landscape has increased in the late period (1870-

541 2014). Although moderate-intensity outbreaks only increased in synchrony, high- and very high-

542 intensity outbreaks saw drastic increases in both frequency and synchrony between the early

543 (pre-1870) and late (post-1869) periods. It is probable that these changes were influenced by

544 changing land-use regimes initiated by western expansion in the $19^{\text {th }}$ century, with impacts like

545 forest homogenization and fire exclusion favoring the expansion of WSB's host species, and thus

546 increasing the likelihood of frequent, widespread WSB outbreaks.

547 Our superposed epoch analyses found strong relationships between landscape- and site-

548 level outbreak histories and moisture availability using both dendroclimatic and observational

549 climate records. Outbreak initiation dates showed a relationship with multiple, consecutive years

550 of low moisture availability in the years preceding initiation events, and consecutive years of

551 high moisture availability during and after initiation years. Cessation dates, on the other hand,

552 showed a strong relationship with high moisture availability during the five years preceding

553 recorded cessation dates. The temporal variability in moisture availability occurring during and

554 around outbreak events supports the pulsed plant stress hypothesis in explaining WSB outbreak

555 dynamics: High moisture stress encourages increases in WSB populations and dispersal rates,

556 and a shift to low moisture stress is necessary to maintain the inflated outbreak-level populations.

557 The results of our study suggest that a complex combination of climate change, land-use

558 patterns, and disturbances such as fires will continue affecting WSB outbreak dynamics in 
559 coming centuries, and continued study is needed to better understand how this complex interplay

560 of exogenous factors will direct WSB populations. Regional and global climate models project a

561 continuing rise in temperatures over the $21^{\text {st }}$ century, while precipitation may be impacted by

562 stronger seasonality, including drier summers (Mote and Salathé 2010). These projected changes

563 will likely increase the frequency of drought conditions necessary for initiating WSB outbreaks.

564 It is also possible that the increase in drought conditions could hamper WSB outbreaks if drought

565 conditions are sustained over too many consecutive years, or occur too frequently, since the

566 climatic reversal warm-dry to consecutive cool-wet conditions appears necessary in sustaining

567 outbreak-level WSB populations. Changes to land-use practices over the next century should

568 also impact the occurrence of WSB outbreaks. A potential increase in forest fire occurrences

569 with a changing climate could lead to changes in the landscape's biomass available to WSB

570 populations, leading to indirect effects on WSB dynamics (Flower et al. 2014b). Additionally,

571 changing climate may drive shifts in the distribution of the WSB's host populations over coming

572 centuries. 


\section{ACKNOWLEDGEMENTS}

We would like to thank Paul Nash of the USFS for his assistance in locating study sites essential for our study. We are also grateful to Connie Mehmel of the USFS for her knowledge of the study area's management history. Dr. Daniel Gavin of the University of Oregon also provided important feedback on our statistical methods. Drs. Andy Bunn and Michael Medler of Western Washington University provided important feedback and guidance during the course of the project. Lastly, this project would not have been possible without the field and lab assistance of Marissa Bhatnagar, Branden Rishel, Christopher Zemp, Venice Wong, Ryan Schumacher, Shelby Van Arnam, Demian Estrada, Derek Huling, and Dustin Gleaves. 


\section{WORKS CITED}

Alfaro, R.I., Berg, J., and Axelson, J. 2014. Periodicity of western spruce budworm in Southern British Columbia, Canada. For. Ecol. Manage., 315, 72-79.

Alfaro, R.I., van Sickle, G.A., Thomson, A.J., and Wegwitz, E. 1982. Tree mortality and radial growth losses caused by the western spruce budworm in a Douglas-fir stand in British Columbia. Can. J. For. Res., 12, 780-787.

Axelson, J.N., Smith, D.J., Daniels, L.D., Alfaro, R.I. 2015. Multicentury reconstruction of western spruce budworm outbreaks in central British Columbia, Canada. For. Ecol. Manage., 335, 235-248.

Brubaker, L.B. 1978. Effects of defoliation by Douglas-fir tussock moth on ring sequences of Douglas-fir and grand fir. Tree-Ring Bull., 38, 49-59.

Bunn, A.G. 2008. A dendrochronology program library in R (dplR). Dendrochronologia, 26, $115-124$.

Buonaccorsi, J.P., Elkinton, J.S., Evans, S.R., and Liebhold, A.M. 2001. Measuring and testing for spatial synchrony. Ecology, 82, 1668-1679.

Campbell, R.W. 1993. Population dynamics of the major North American needle-eating budworms. USDA For. Serv. Res. Pap. PNW-RP-463.

Campbell, R., Smith, D.J., and Arsenault, A. 2006. Multicentury history of western spruce budworm outbreaks in interior Douglas-fir forests near Kamloops, British Columbia. Can. J. For. Res., 36, 1758-1769.

Chen, P.-Y., Welsh, C., Hamann, A. 2010. Geographic variation in growth response of Douglasfir to interannual climate variability and projected climate change. Glob. Chang. Biol., 16, 3374-3385. 
Chiang, C.Y., and Reese, M. 2002. Evergreen state: Exploring the history of Washington's forests. Center for the Study of the Pacific Northwest, University of Washington, WA.

Clancy, K.M. 1991. Western spruce budworm response to different moisture levels in artificial diets. For. Ecol. Manage. 39, 223-235.

Cook, E.R. 1985. A time-series analysis approach to tree-ring standardization. Ph.D. unpublished thesis, University of Arizona, AZ.

Cook, E.R., Woodhouse, C.A., Eakin, C.M., Meko, D.M., and Stahle, D.W. 2004. Long-term aridity changes in the Western United States. Science, 306, 1015-1018.

Coops, N.C., and Waring, R.H. 2011. A process-based approach to estimate lodgepole pine (Pinus contorta Dougl.) distribution in the Pacific Northwest under climate change. Clim. Chang., 105, 313-328.

Fellin, D.G., and Dewey, J.F. 1982. Western spruce budworm. Forest Insect and Disease Leaflet 53. USDA For. Serv. Forest Insect and Disease Leaflet 53.

Flower, A. 2016. Three centuries of synchronous forest defoliator outbreaks in western North America. PLoS ONE, 11, e0164737. doi:10.1371/journal.pone.0164737

Flower, A., Gavin, D.G., Heyerdahl, E.K., Parsons, R.A., and Cohn, G.M. 2014a. Droughttriggered western spruce budworm outbreaks in the interior Pacific Northwest: A multicentury dendrochronological record. For. Ecol. Manage., 324, 16-27.

Flower, A., Gavin, D.G., Heyerdahl, E.K., Parsons, R.A. and Cohn, G.M. 2014b. Western spruce budworm outbreaks did not increase fire risk over the last three centuries: A dendrochronological analysis of inter-disturbance synergism. PLoS ONE, 9, e114282. doi:10. 1371/journal.pone.0114282

Gavin, D.G. 2010. K1D: Multivariate Ripley’s K-function for one-dimensional data (Ver. 1.2) 
[software]. Accessed via http://geog.uoregon.edu/envchange/software/K1D_1.pdfs

[accessed June 2015].

Gavin, D.G., Hu, F.S., Lertzman, K.P., and Corbett, P. 2006. Weak climatic control of forest fire history during the late Holocene. Ecology, 87, 1722-1732.

Gedalof, Z., and Smith, D.J. 2001. Interdecadal climate variability and regime-scale shifts in Pacific North America. Geophys. Res. Lett., 28, 1515-1518.

Gower, S.T., Vogt, K.A., and Grier, C.C. 1992. Carbon dynamics of Rocky Mountain Douglasfir: Influence of water and nutrient availability. Ecol. Monogr., 62, 43-65.

Greenbank, D.O., Schaefer, G.W., and Rainey, R.C. 1980. Spruce budworm (Lepidoptera: Tortricidae) moth flight and dispersal: New understanding from canopy observations, radar, and aircraft. Mem. Entomol. Soc. Can., 110, 1-49.

Grissino-Mayer, H.D. 2001. FHX2--Software for analyzing temporal and spatial patterns in fire regimes from tree rings. Tree-Ring Res., 57, 115-124.

Hadfield, J.S., Mathiasen, R.L., and Hawksworth, F.G. 2000. Douglas-fir dwarf mistletoe. USDA For. Serv. Forest Insect and Disease Leaflet 54.

Hard, J.S., Tunnock, S., and Eder, R.G. 1980. Western spruce budworm defoliation trend relative to weather in the Northern Region, 1969-1979. USDA For. Serv. Rep. No. 80-4.

Harris, J.W.E., Alfaro, R.I., Dawson, A.F., and Brown, R.G. 1985. The western spruce budworm in British Columbia 1909-1983. Can. For. Serv. Information Report BC-X-257.

Hessburg, P.F., Mitchell, R.G., Filip, G.M. 1994. Historical and current role of insects and pathogens in eastern Oregon and Washington forest landscapes. USDA For. Serv. Gen. Tech. Rep. PNW-GTR-327. 
Huberty, A.F., and Denno, R.F. 2004. Plant water stress and its consequences for herbivorous insects: A new synthesis. Ecology, 85, 1383-1398

Jenkins, M.L. 2015. Major forest insect and disease conditions in the United States: 2013. USDA For. Serv. Rep. FS-1054.

Johnson, E.W., and Ross, J. 2008. Quantifying error in aerial survey data. Aust. For., 71, 216222.

Keane, R.E., Pasons, R., \& Hessburg, P.F. 2002. Estimating historical range and variation of landscape patch dynamics: limitations of the simulation approach. Ecological Modeling, 151, 29-49.

Larsson, L.-A., and Larsson, P.O. 2014. CDendro and CooRecorder (v. 7.8.1) [software]. Saltsjöbaden, Sweden: Cybis Elektronik and Data AB. Available from http://www.cybis.se [accessed December 2014].

Lasmanis, R., and Cheney, E.S. 1994. Regional Geology of Washington State. Symposium on the Regional Geology of the State of Washington, 1992.

Liebhold, A., Koenig, W.D., and Bjørnstad, O.N. 2004. Spatial synchrony in population dynamics. Annu. Rev. Ecol. Evol. Syst., 35, 467-490.

Little, E.L. 1971. Atlas of United States trees, vol. 1, conifers and important hardwoods. Washington, D.C.: U.S. Department of Agriculture, Forest Service.

Lynch, A.M. 2007. What tree-ring reconstruction tells us about conifer defoliator outbreaks. In Insect Outbreaks Revisited, edited by P. Barbosa, D. Letourneau, and A. Agrawal. WileyBlackwell, Chichester, U.K. pp. 126-155. 
Maclauchlan, L.E., and Brooks, J.E. 2009. Influence of past forestry practices on western spruce budworm defoliation and associated impacts in southern British Columbia. BC. J. Ecosys. Manage. 10, 37-49. 
Maclauchlan, L.E., Brooks, J.E., and Hodge, J.C. 2006. Analysis of historic western spruce budworm defoliation in south central British Columbia. For. Ecol. Manage., 226, 351356.

Mason, R.R., Wickman, B.E., Paul, H.G. 1997. Radial growth response of Douglas-fir and grand fir to larval densities of the Douglas-fir tussock moth and the western spruce budworm. For. Sci., 43, 194-205.

Mattson, W.J., and Haack, R.A. 1987. The role of drought in outbreaks of plant-eating insects. BioScience, 37, 110-118.

McComb, D. 1979. Evaluation of the 1979 western spruce budworm outbreak on selected areas of the Okanogan National Forest. USDA For. Serv., Portland, OR.

McNab, W.H., and Avers, P.E. 1994. Ecological subregions of the United States. Washington, D.C.: U.S. Department of Agriculture, Forest Service. Available from http://www.fs.fed.us/land/pubs/ecoregions/ [accessed August 2014].

Mody, K., Eichenberger, D., and Dorn, S. 2009. Stress magnitude matters: Different intensities of pulsed water stress produce non-monotonic resistance responses of host plants to insect herbivores. Ecol. Entomol., 34, 133-143.

Moran, P.A.P. 1953. The statistical analysis of the Canadian lynx cycle. Aust. J. Zool., 1, 291298.

Mote, P.W., and Salathé, E.P. 2010. Future climate in the Pacific Northwest. Clim. Chang., 102, $29-50$.

Nash, T.H., Fritts, H.C., and Stokes, M.A. 1975. A technique for examining non-climatic variation in widths of annual tree rings with special reference to air pollution. Tree-Ring Bull., 35, 15-24. 
Nealis, V.G. 2015. Comparative ecology of conifer-feeding spruce budworms (Lepidoptera: Tortricidae). Can. Entomol., 00, 1-25.

NOAA. 2015. Climate Division 7. NOAA’s Gridded Climate Divisional Dataset (CLIMDIV) [online]. NOAA National Climatic Data Center. Available from https://www.ncdc.noaa.gov/monitoring-references/maps/us-climate-divisions.php [accessed May 2015].

Palmer, W.C. 1965. Meteorological Drought. Department of Commerce Weather Bureau Res. Pap. No. 45 .

Peltonen, M., Liebhold, A.M., Bjørnstad, O.N., and Williams, D.W. 2002. Spatial synchrony in forest insect outbreaks: Roles of regional stochasticity and dispersal. Ecology, 83, 3120_ 3129. 
R Core Team. 2013. R: A language and environment for statistical computing [software]. R Foundation for Statistical Computing. Vienna, Austria. Available from http://www.Rproject.org/ [accessed January 2015].

Ryerson, D.E., Swetnam, T.W., and Lynch, A.M. 2003. A tree-ring reconstruction of western spruce budworm outbreaks in the San Juan Mountains, Colorado, U.S.A. Can. J. For. Res., 33, 1010-1028.

Shepherd, R.F. 1994. Management strategies for forest insect defoliators in British Columbia. For. Ecol. Manage., 68, 303-324.

Speer, J.H. 2010. Fundamentals of Tree Ring Research. University of Arizona Press, Tucson, AZ.

Swetnam, T.W., and Lynch, A.M. 1993. Multicentury, regional-scale patterns of western spruce budworm outbreaks. Ecol. Monogr., 63, 399-424.

Swetnam, T.W., Thompson, M.A., and Sutherland, E.K. 1985. Using dendrochronology to measure radial growth of defoliated trees. USDA For. Serv. Handbook 639.

Swetnam, T.W., Wickman, B.E., Paul, H.G., and Baisan, C.H. 1995. Historical patterns of western spruce budworm and Douglas-fir tussock moth outbreaks in the northern Blue Mountains, Oregon, since A.D. 1700. USDA For. Serv. Res. Pap. PNW-RP-484.

Thomson, A.J., Shepherd, R.F., Harris, J.W.E., and Silversides, R.H. 1984. Relating weather to outbreaks of western spruce budworm, Choristoneura occidentalis (Lepidoptera: Tortricidae), in British Columbia. Can. Entomol., 116, 375-381.

USDA Forest Service. 1977. USDA 1977 draft environmental statement, addendum to the final 1976 cooperative western spruce budworm pest management plan. USDA For. Serv. Rep. R6-DES(ADM)-76-7. 
USDA Forest Service. 2014. Insect and Disease Surveys [online]. Forest Health Protection, Arizona State Forestry Division and New Mexico State Forestry Division. USDA For. Serv. Available from http://www.fs.fed.us/foresthealth/technology/adsm.shtml [accessed July 2014].

Wang, T., Harmann, A., Spittlehouse, D., and Murdock, T.N. 2012. ClimateWNA--highresolution spatial climate data for Western North America. J. Appl. Meteorol. Climatol., 26, 383-397.

Watson, E., and Luckman, B.H. 2002. The dendroclimatic signal of Douglas-fir and ponderosa pine tree-ring chronologies from the southern Canadian Cordillera. Can. J. For. Res., 32, $1858-1874$.

Westfall, J., and Ebata, T. 2014. 2014 summary of forest health conditions in British Columbia. Forest Practices Branch Pest Manage. Rep. No. 15.

Wickman, B.E. 1992. Forest health in the Blue Mountains: The influence of insects and diseases. USDA For. Serv. Gen. Tech. Rep. PNW-GTR-295.

Willhite, E.A., and Stock, M.W. 1983. Genetic variation among western spruce budworm (Choristoneura occidentalis (Lepidoptera: Tortricidae) outbreaks in Idaho and Montana. Can. Entomol., 115, 41-54.

Williams, D.W., and Birdsey, R.A. 2003. Historical patterns of spruce budworm defoliation and bark beetle outbreaks in North America conifer forests: An atlas and description of digital maps. USDA For. Serv. Gen. Tech. Rep. NE-308. 


\section{TABLES}

Table 1

Site and chronology characteristics for our four host (Douglas-fir) sites and three non-host (ponderosa pine) sites in the Okanogan Highlands.

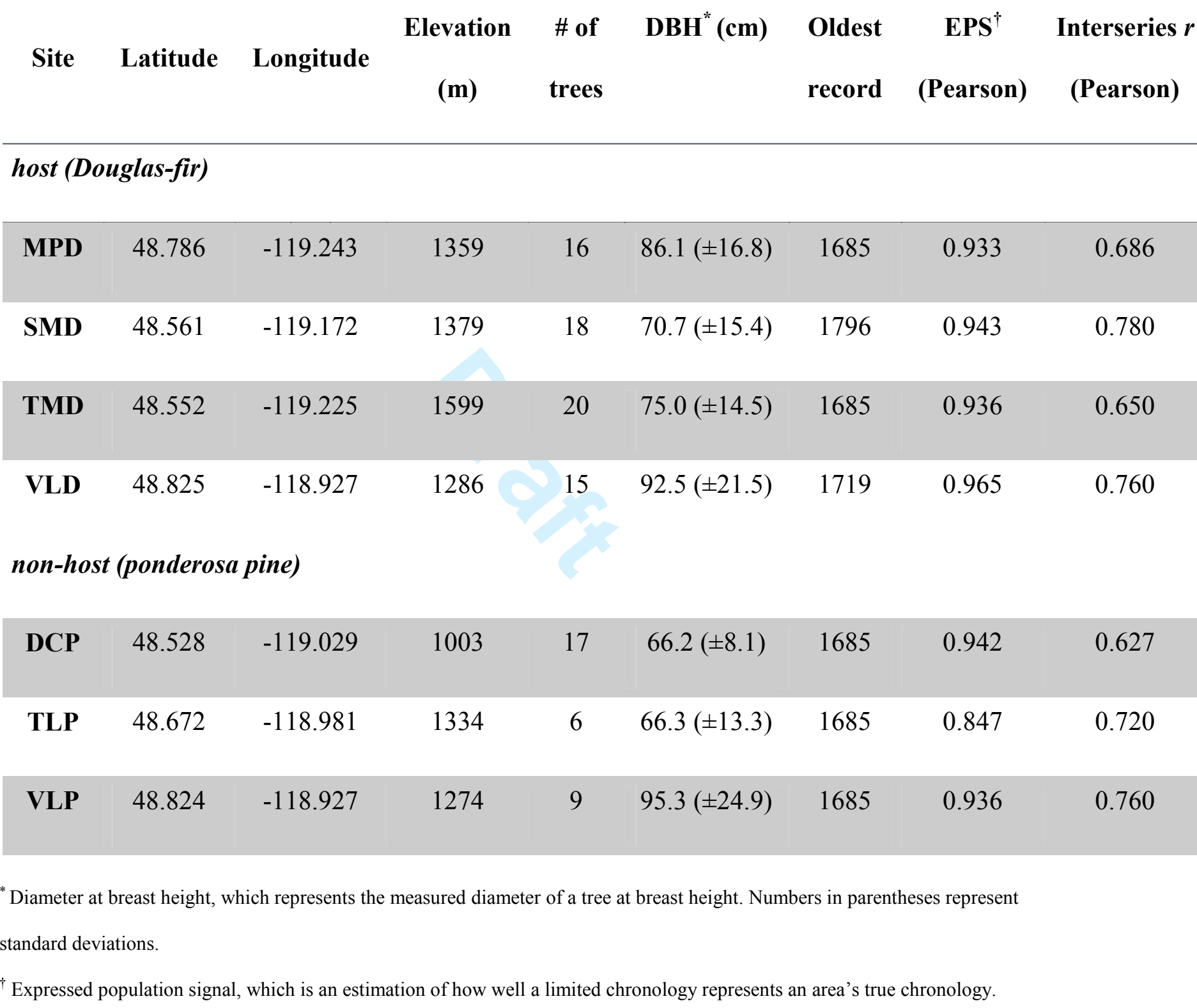


Table 2

Cross-correlation (Pearson's $r ; p<0.05$ except where noted) values of residual host (Douglas-fir) chronologies and the landscape's non-host (ponderosa pine) chronology against reconstructed (1685-2003) and historical (1895-2014) climate data for the Okanogan Highlands.

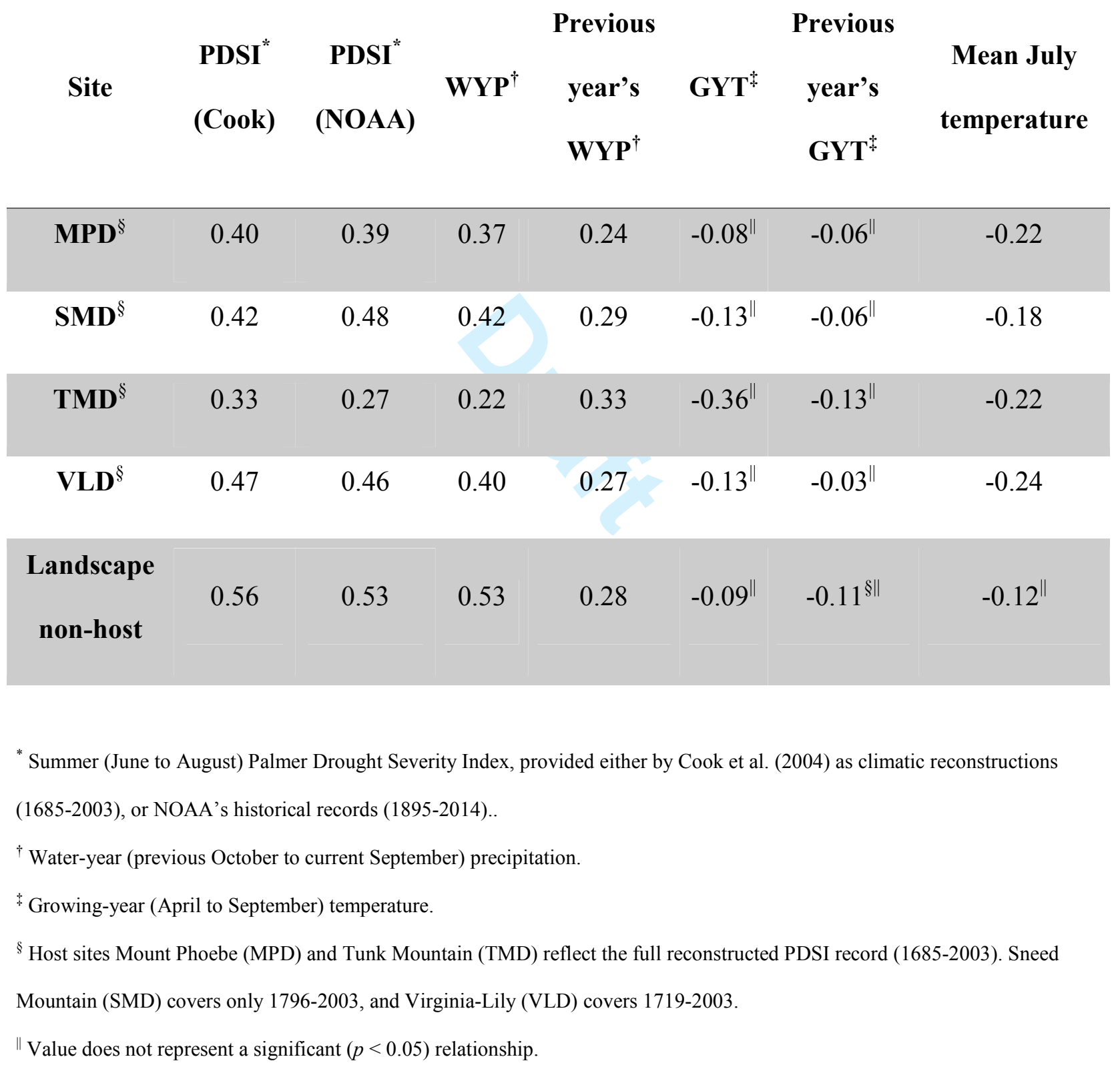


Table 3

Outbreak statistics for our four Douglas-fir host sites (MPD, SMD, TMD, and VLD), and our landscape-wide outbreak record in the Okanogan Highlands. Numbers in parentheses represent standard deviation.

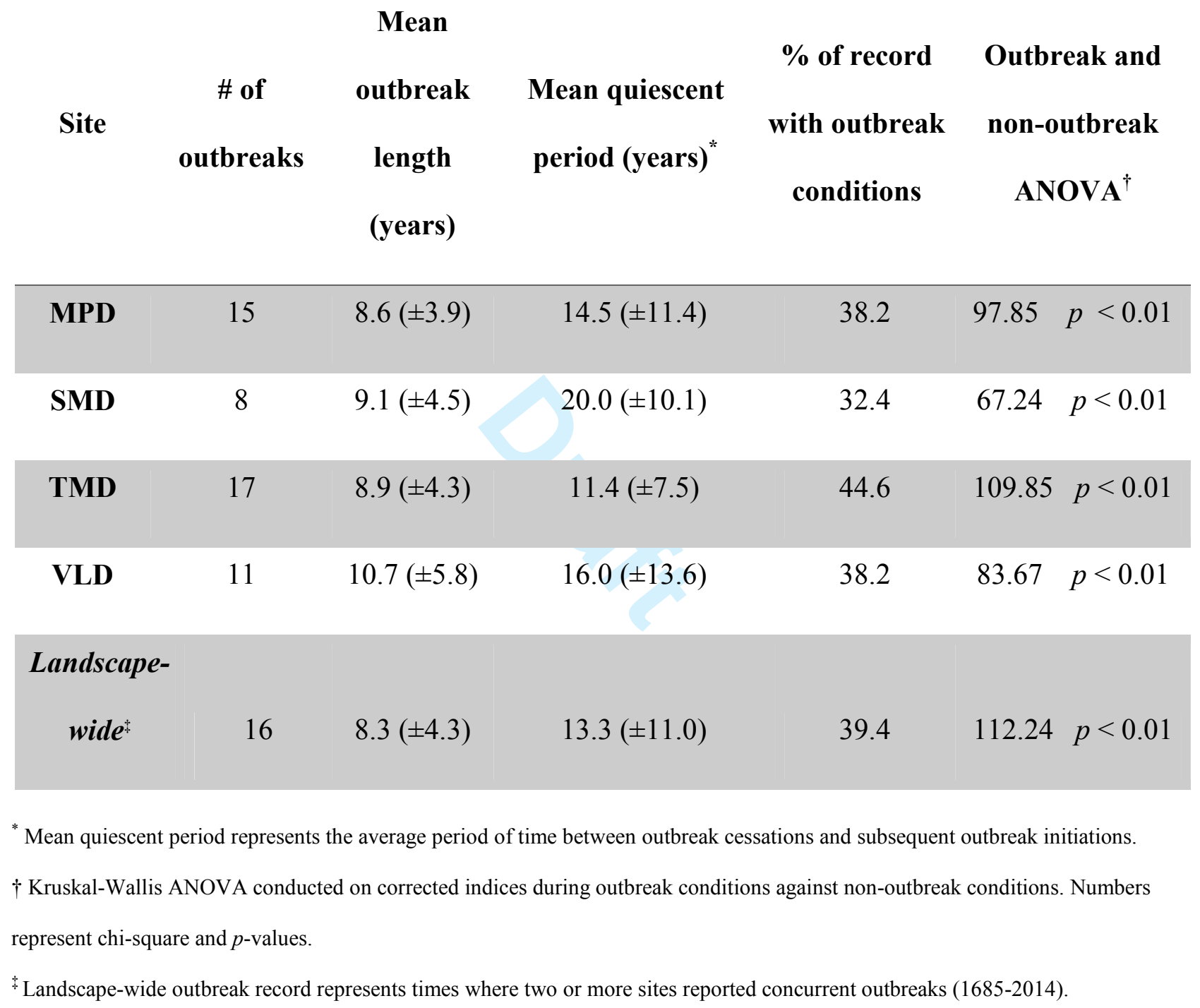


Table 4

Percent of outbreak years occurring in the early (1685-1869) and modern (1870-2014) periods using moderate ( $40 \%$ of trees), high ( $60 \%$ of trees), and very high ( $80 \%$ of trees) outbreak intensity thresholds. MPD, SMD, TMD, and VLD represent our four Douglas-fir host sites in the Okanogan Highlands, and the landscape-wide record represents time when two or more sites reported outbreak conditions.

\begin{tabular}{|c|c|c|c|c|c|c|}
\hline \multirow{2}{*}{ Site } & \multicolumn{2}{|c|}{ Moderate } & \multicolumn{2}{|c|}{ High } & \multicolumn{2}{|c|}{ Very high } \\
\hline & Early & Late & Early & Late & Early & Late \\
\hline MPD & 34.1 & 43.4 & 21.6 & 23.4 & 5.9 & 14.5 \\
\hline SMD & 20.3 & 38.6 & 8.1 & 22.1 & 0.0 & 6.9 \\
\hline TMD & 41.6 & 48.3 & 6.5 & 26.9 & 2.2 & 11.7 \\
\hline VLD & 33.8 & 42.8 & 13.9 & 22.1 & 2.6 & 13.1 \\
\hline $\begin{array}{c}\text { Landscape- } \\
\text { wide }\end{array}$ & 30.8 & 50.3 & 9.7 & 28.3 & 0.0 & 14.5 \\
\hline
\end{tabular}

Note: Percents shown are the total number of years within each period's length. Each of our four sites are represented, as well as the landscape-wide outbreak history with at least two sites reporting outbreaks concurrently. SMD (1796-2014) and VLD (17192014) do not represent equal measures of time between early and modern periods. Landscape-wide outbreaks record represents times where two or more sites reported concurrent outbreaks (1685-2014). 


\section{FIGURE CAPTIONS}

Fig. 1

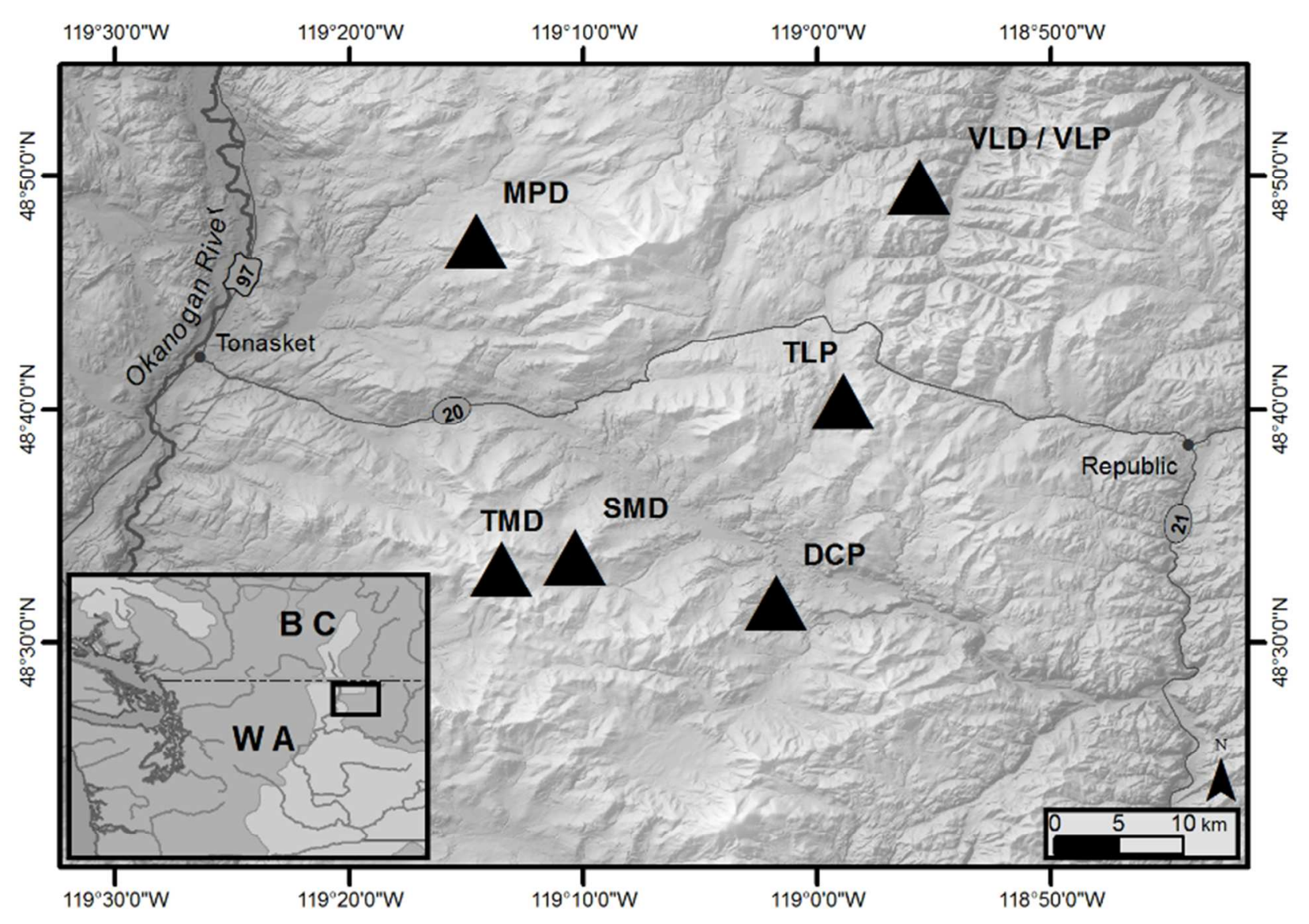

Location of host (Douglas-fir) and non-host (ponderosa pine) sites within the Okanogan

Highlands. Significant local features include the highest peak, Mount Bonaparte, immediately east of site MPD, and the Aeneas Valley dividing our southern sites from our northern locations.

Shaded region on the inset map represents distribution of Douglas-fir, provided by Little (1971).

Digital elevation model courtesy of the U.S. Geological Survey.

Fig. 2 


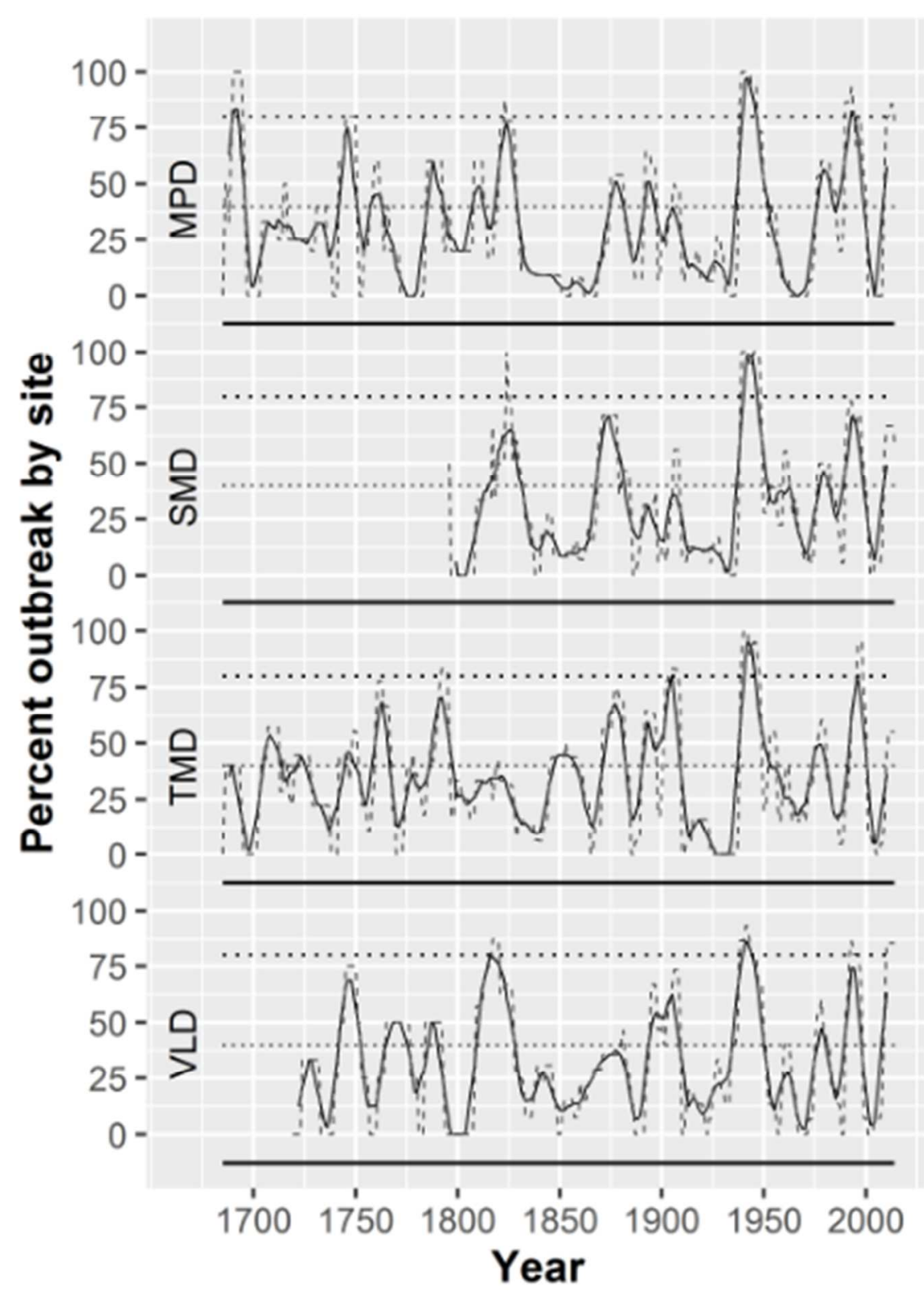

Percent of trees recording an outbreak at our four Douglas-fir host sites. Solid black lines represent an 8-year moving average of the percent of trees returning outbreak records, and the dashed line represents the unfiltered outbreak records. The two dotted straight lines indicate two of our outbreak intensity levels, wherein our sites have at least $40 \%$ (moderate) and $80 \%$ (very high) of the sampled trees reporting outbreak conditions

Fig. 3 

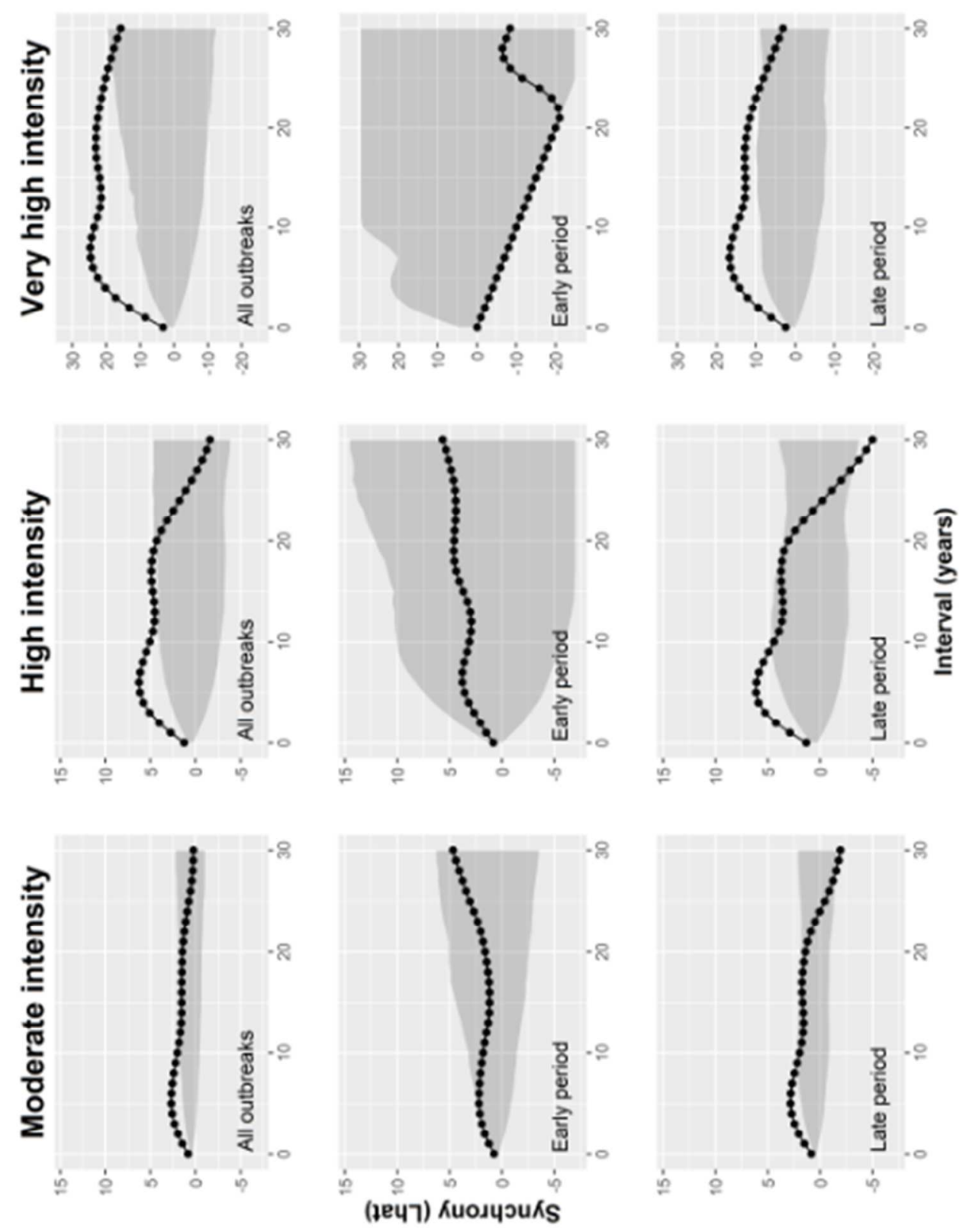

Modified Ripley's K-function calculated for all outbreak years (1719-2014) in the Okanogan Highlands using moderate ( $40 \%$ of sampled trees reporting outbreak conditions), high (60\%), and very high $(80 \%)$ outbreak intensities. The top image represents all years of data. The middle and bottom images separate the outbreak years between early (1719-1869) and late (1870-2014) periods. Note the change to the y-axis due to the decreased sample sizes for very high-intensity outbreaks. 
Fig. 4

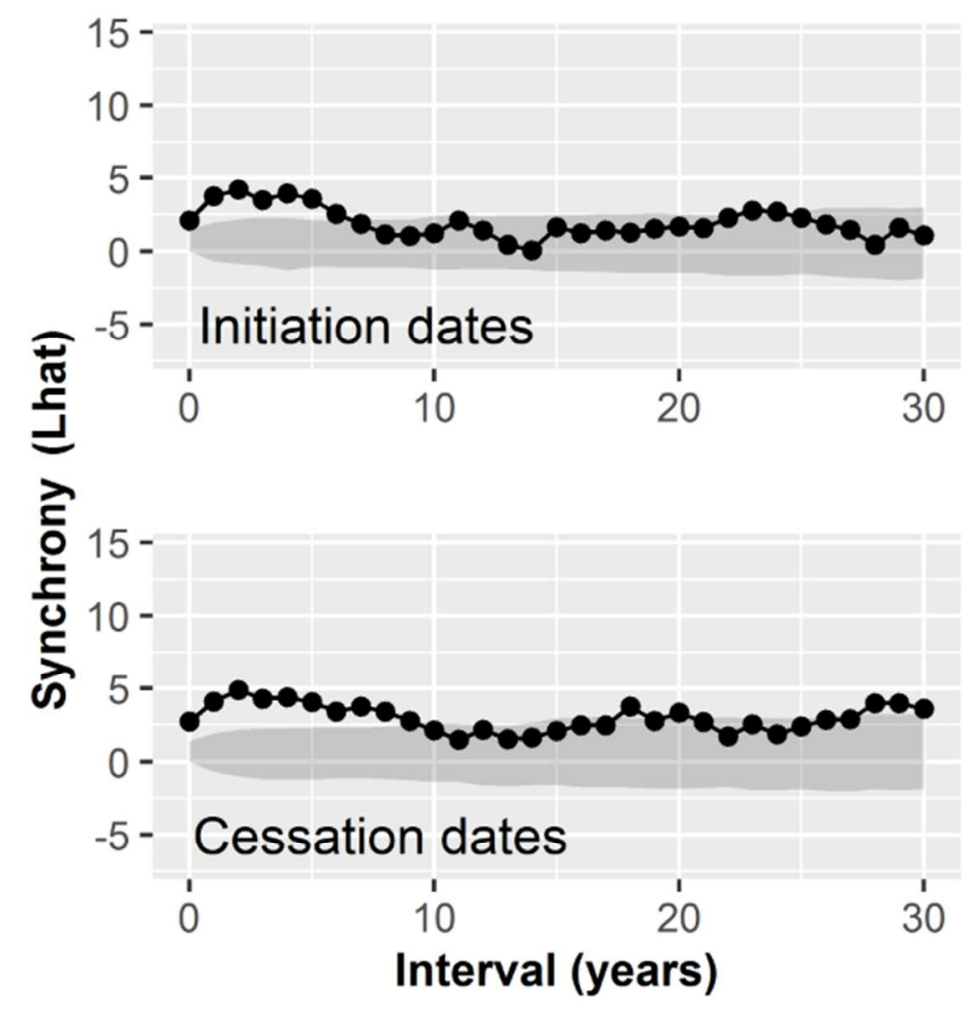

Modified Ripley's K-function for moderate outbreak initiation dates and cessation dates. All dates were taken from our three host Douglas-fir sites dating to 1719 to include as much of the record with as many of our sites as we could. Y-axis represents a level of synchrony (positive) or asynchrony (negative) calculated using the temporal window (one to 30 years) shown on the $\mathrm{x}$ axis, with the shaded region representing the confidence interval (95\%).

Fig. 5 

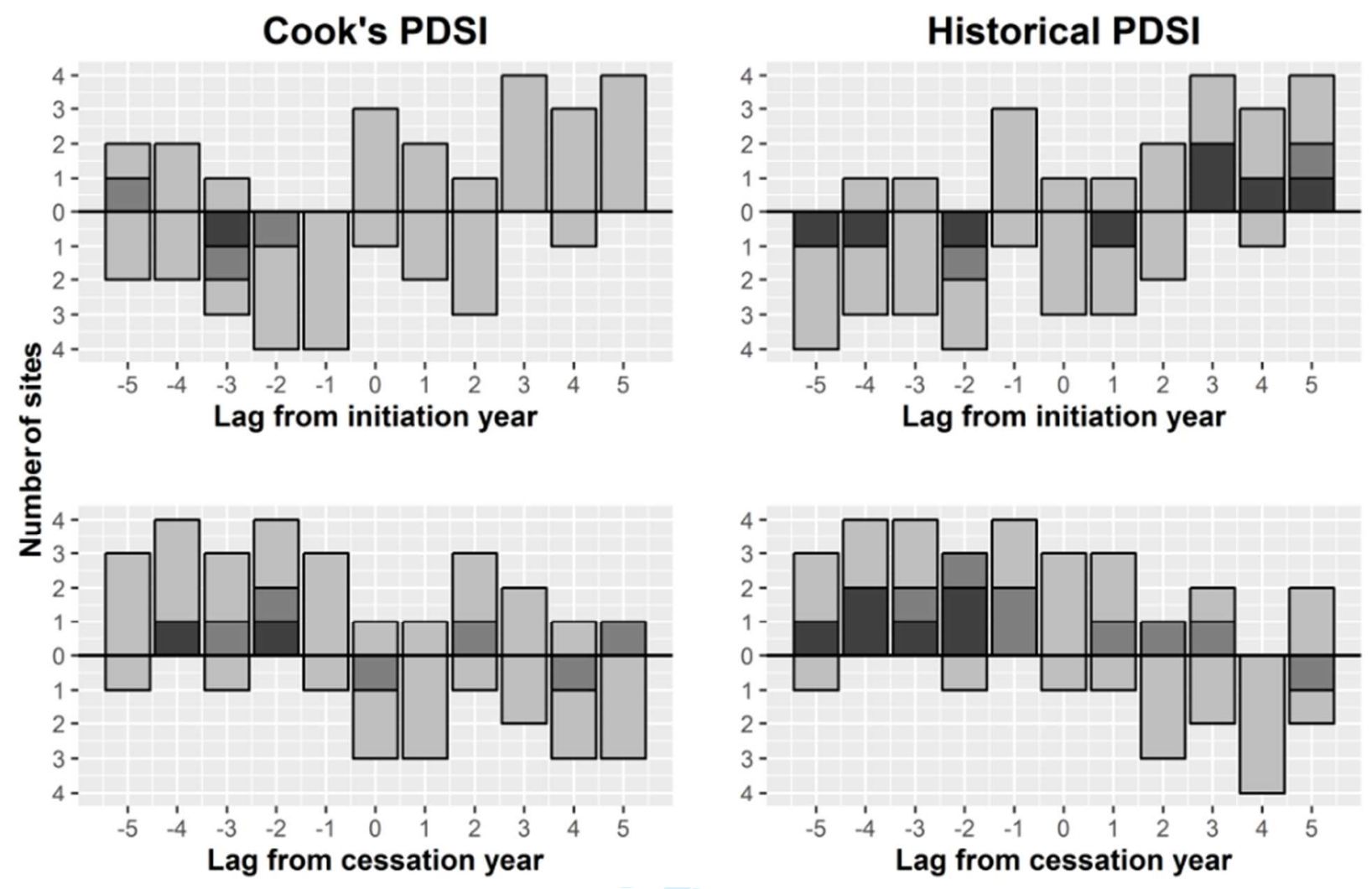
Summary of superposed epoch analysis summary of our four host Douglas-fir sites' initiation (first year of outbreak) and cessation (first year of non-outbreak conditions following an outbreak) dates using Cook et al.'s (2004) PDSI reconstructions (1685-2003) and historical (1895-2014; NOAA 2015) PDSI records. Ascending bars represent number of sites with positive PDSI anomaly, descending bars represent number of sites with a negative PDSI anomaly. Instances of high significance are noted by dark grey (90\%) and black (95\%) shading. Fig. 6
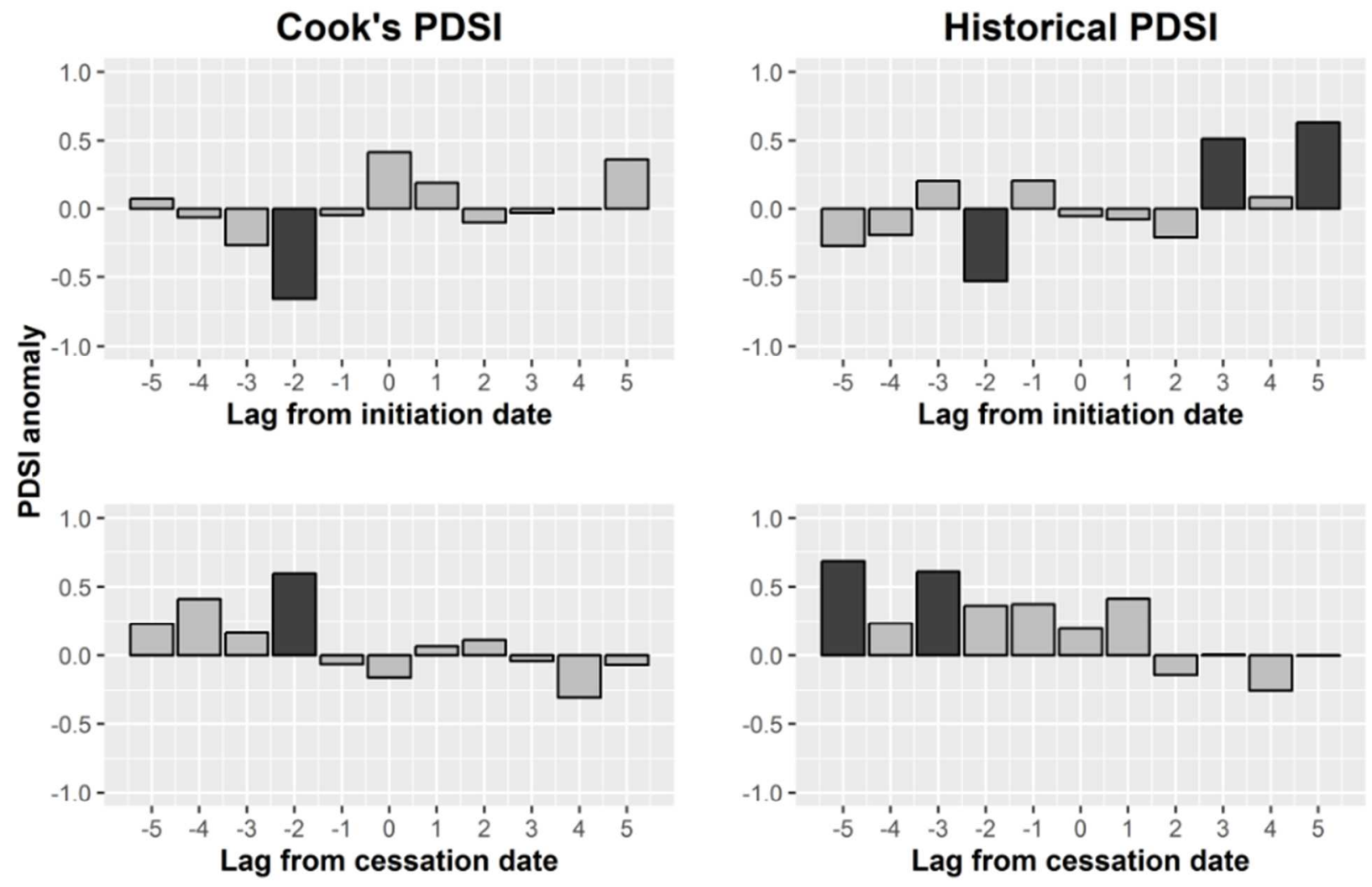

Superposed epoch analysis using the landscape-wide outbreak initiation and cessation dates for the Okanogan Highlands. We used Cook et al.'s (2004) PDSI reconstructions (1685-2003) and historical (1895-2014; NOAA 2015) PDSI records. Ascending and descending bars represent positive and negative departures from the mean, respectively. Instances of high significance 
(95\%) are noted by black shading. 